\title{
3D Body Scanners' Ability to Improve the Cutting of Patterns for Traditional Saudi Garment to Assimilate them into Modern-day Clothing
}

\author{
Faizah ALMALKI *, Simeon GILL, Steven G. HAYES, Lisa TAYLOR \\ The University of Manchester, Manchester, UK
}

\begin{abstract}
https://doi.org/10.15221/20.25
Abstract

3D body scanning and CAD tools offer opportunities to develop traditional pattern cutting methods, that better contextualise the body, whilst retaining the traditional appearance. The costumes that are traditional to a particular region of Saudi Arabia represent a key aspect of that area's cultural identity. These traditional costumes offer a glimpse at the region's heritage and how this has evolved throughout history. Current pattern drafting methods that utilise flat patterns are relatively simple compared to the traditional methods based on a one-to-one interaction with the person who would ultimately wear the finished garment. There are various measurements required for each method for example, (Bust circumference, Waist circumference, Hips, Shoulder, back length, Sleeve length, Bust-length, Waist to Hip, Chest, Neck size, Back width, Nape to the waist, Armscye depth, Pattern length, Wrist, Sleeve length). This paper focuses on how traditional methods for creating Saudi Arabian garment can be enhanced through the use of 3D body scanning. Specifically focusing on the traditional Sawwan garment, a traditional dress, and developing a thorough understanding of the traditional methods the benefits afforded by 3D body scanners can be incorporated to enhance the process. Body scanners offer a highly efficient means of measuring various parts of the human body that can then be used to produce well-fitted garments. Scanners also provide opportunities for new measurements which are more difficult to capture using existing manual tools. Traditionally all aspects of the process apply little technology, from the taking of body measurements, the construction process and the use of geometric shapes. Body scanners have opened up new opportunities to take more measurements in quickly, thereby ensuring that the human form can be central in the pattern construction process. Whilst still making use of 2D pattern drafting methods, this study utilises additional measurements when producing pattern blocks so as to ensure that the resulting garments can more accurately reflect the wearer's shape and proportions. In addition to taking measurements using a Size Stream body scanner, the current study assesses a well-known garment draft based on measurements taken with the scanner relative to an innovative means of garment drafting that makes full use of the body scanner's precision. Accordingly, digitally tailored garments need to precise measurements as a key to make a well-fitting garment. Besides, the current research will hopefully encourage others to explore how technology can retain traditional designs and improve our understanding of pattern theory. Results indicate that the scanner can provide data in more depth than traditional approaches. Therefore, the current study extends the existing knowledge base, by using body scanning to enhancing the system of patternmaking. This enables the creation of custom computer-aided pattern drafting, thereby improving the range of clothing available in the Saudi market.
\end{abstract}

Keywords: Sawwan garment system,3D Body Scanning, anthropometrics and Bespoke garment construction

\section{Introduction and background}

A core element of a community's cultural identity is their traditional costumes which reflect their heritage in designs that have evolved over many generations. Heritage can be reflected in the functional uses of the garments but also in the choice of dyes and shapes which are often indicative of the skills of the maker and the status of the wearer depending on how time-consuming they are to produce. Traditional methods are often more complicated than the modern approaches used to produce patterns such as flat drafting because the traditional approaches typically involve fabric being draped over the body and repeated direct engagement with the wearer during the construction process. The traditional costumes worn by women in Saudi Arabia provide a good indication of their resourcefulness, using what was readily available in the local setting [1]. However, the discovery of oil in the country transformed not only the domestic economy but also many aspects of society and culture. This has generally resulted in Western civilisation exerting considerable influence on the people of Saudi Arabia and this is reflected

"faizah.almalki@manchester.ac.uk 
in their lifestyles as well as the technologies they use [2]. The influence of Western civilisations has also extended to women's clothing and is reflected in the accuracy and versatility of manufacturing processes in the garment industry, thereby enabling fashion designs from around the globe to be offered for sale in Saudi Arabia [3]. Many women in Saudi Arabia have acquired a taste for luxury and this is evidence in their choice of clothes (see Figure 1).

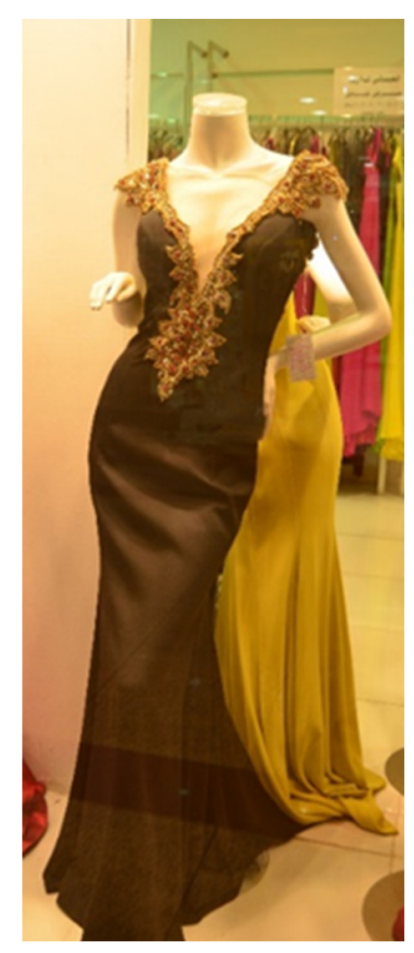

Figure 1 show the influence of modern style in Saudi women life

The current study examines the traditional garment (Sawwan, 1958) worn by women of the Bani Malik region of Saudi Arabia (see Figure 2). Curiously, there are no documented instructions setting out how such garments are constructed, rather, it is necessary to rely on descriptions of the garments provided in illustrations and written testimonies to understand how they could be made $[2,3,4,5,6]$.

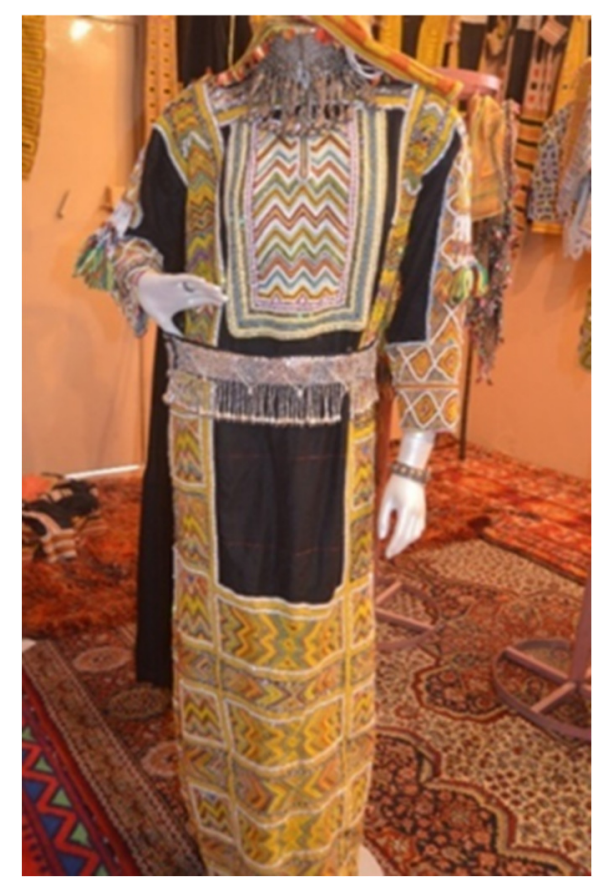

Figure 2 traditional Sawwan garment that worn by women in Bani Malik, 1958 
Therefore, the current study provides a detailed account of the pattern cutting system used to produce Sawwan garments and how this has changed over time regarding Saudi dress and the external influences that have been reflected in the design of Sawwan garments. An interview is used to provide insight to help develop a framework whereby the latest technology can be deployed to produce traditional clothing. By utilising the data produced by body scanners, it is possible to improve on the methods by which pattern blocks (Slopers) are drafted [7]. Indeed, it is widely acknowledged that body scanners provide considerably more data relating to the form of the human body than is possible to generate when relying solely on traditional measurements [8]. There is considerable scope for 3D body scanners to be used in the garment industry. [9] noted that such scanners are able to make as many measurements of the human body as required in just a few seconds. What is more, owing to the fact that the scanning process results in an image of the body being produced, it is possible to quickly change the description or location of any measurements, as required. A further advantage associated with using a body scanner is that the measurements taken will be more accurate than those taken manually. Furthermore, the fact that numerous linear and non-linear measurements can be taken by these scanners creates an opportunity for garments to be produced that are exceptionally well fitted so that they truly mould to the human form. A further benefit is that because the measurements are recorded digitally, there is the possibility to link the scanner to apparel CAD systems, thereby removing the need for human involvement in the process and reducing the possibility for errors. Essentially, the application of 3D body scanners makes it financially viable for customised garments to be mass produced. The current study has made use of traditional draping methods and styles whilst considering taking additional measurements than those usually relied upon when creating patterns. This new approach will result in blocks that provide a truer reflection of the wearer's shape, size and proportions. In addition to using a Size Stream body scanner to assist with pattern development, the current study has demonstrated the range of measurements that body scanners are able to take. As such, in future this will help to manufacturers to produce better fitting and more functional garments by making use of body scanners. Therefore, the current study demonstrates one way in which the relatively new body scanning technology can be effectively combined with traditional dress and pattern making methods to present opportunities in the garment industry. The traditional approaches used to produce Sawwan garments would not involve the taking of many measurements such as those of the bust circumference or hips. As such, this research will expand the knowledge base, utilising body scanning technology to improve how patterns are made. Because the computer does much of the work, it is feasible to produce customised patterns and enhance the range of garments available to customers, thereby helping to promote traditional styles that are more functional and can be worn on a day-to-day basis by modern women who are keen to retain elements of tradition in their styling.

\section{Method}

The current research will employ the following methods:

\subsection{Producing patterns for Sawwan garments using established practices}

This study is being undertaken in order to improve the existing body of knowledge regarding to produce patterns and construct for Sawwan garments (Sawwan, 1958). Interviews have provided valuable insight in the form of qualitative data to inform how measurements would have traditionally been taken to produce Sawwan patterns. Audio and video recordings of the interviews were taken and observations were made, with illustrations to support the findings.

The qualitative data were collected from five people who derive an income from producing Sawwan. In accordance with the criteria specified for the current study, each of the participants were female, at least fifty years of age and expert in producing Sawwan garments. Care must be taken when selecting suitable participants to ensure that they will provide reliable insight into the production of Sawwan garments. Convenience sampling was used with the first participant being known to the researcher. Subsequently, snowball sampling was utilised whereby the participants recommended others who they thought may have useful insight. 


\subsection{Process for the proposed Sawwan pattern method}

Knowledge of the body-to-pattern shape relationships used in pattern making can be used to improve methods for the mass customisation of garments [10]. Having created a pattern block for a garment, this can then be adjusted to produce a more tailored item of clothing [11]. The best aspects of three different pattern making methods were used to create a new approach that would produce better fitting garments while retaining the heritage of the Sawwan garment and the traditional approaches to pattern making. Each of the three methods was carefully studied to establish the ease allowances applied at the hips, waist and bust and understand where darts should be placed as well as the percentage suppression used to shape the waist and bust. The current study sets out to draft a Sawwan pattern block drawing upon the modern measuring process of a 3D body scanner.

The necessary measurements were obtained using a Size Stream SS20 body scanner. The first step was to map the measurements necessary for the Aldrich 2015 based on default measurements in accordance with the approach taken when previously researching Sawwan garments and when it was not possible to obtain measurements, these were created using the custom measurement tool. Custom measurements were developed using the Size Stream Studio 5.2.9 software. In the event that a direct match could not be achieved, a new measurement was defined whereby the result would be a value obtained from the human form that closely mirrored the value in the draft process. One of the main advantages associated with the Aldrich 2015 approach is that the measurements required are accurately described.

The process of fit testing focuses on certain locations and makes certain that the garments produced satisfy the stated criteria. Three independent experts undertook the fit testing, each following the same criteria to appraise the fit at certain parts of the body. This method helped with the custom draft process where revisions are needed.

Subsequently, the garment production methods were coded using plots to enable an automated approach to drafting, whereby the body scanner supplies the necessary data to the software. This involved additional tests and prompted a series of questions regarding pattern theory that would ultimately improve the automation of pattern block construction.

\section{Results and discussion}

Having conducted the interviews with the experts, it became apparent that it was women who would typically take measurements for their entire household and customise garments to suit each member of the family using basic equipment. This would essentially involve Sawwan garments being created using rudimentary measurements for the length of the sleeve, the width of the neck, wrist and shoulders, the length of the armpit and the total length (see Figure 3). However, relying solely on these few measurements cannot consistently produce comfortable, well-fitted garments.

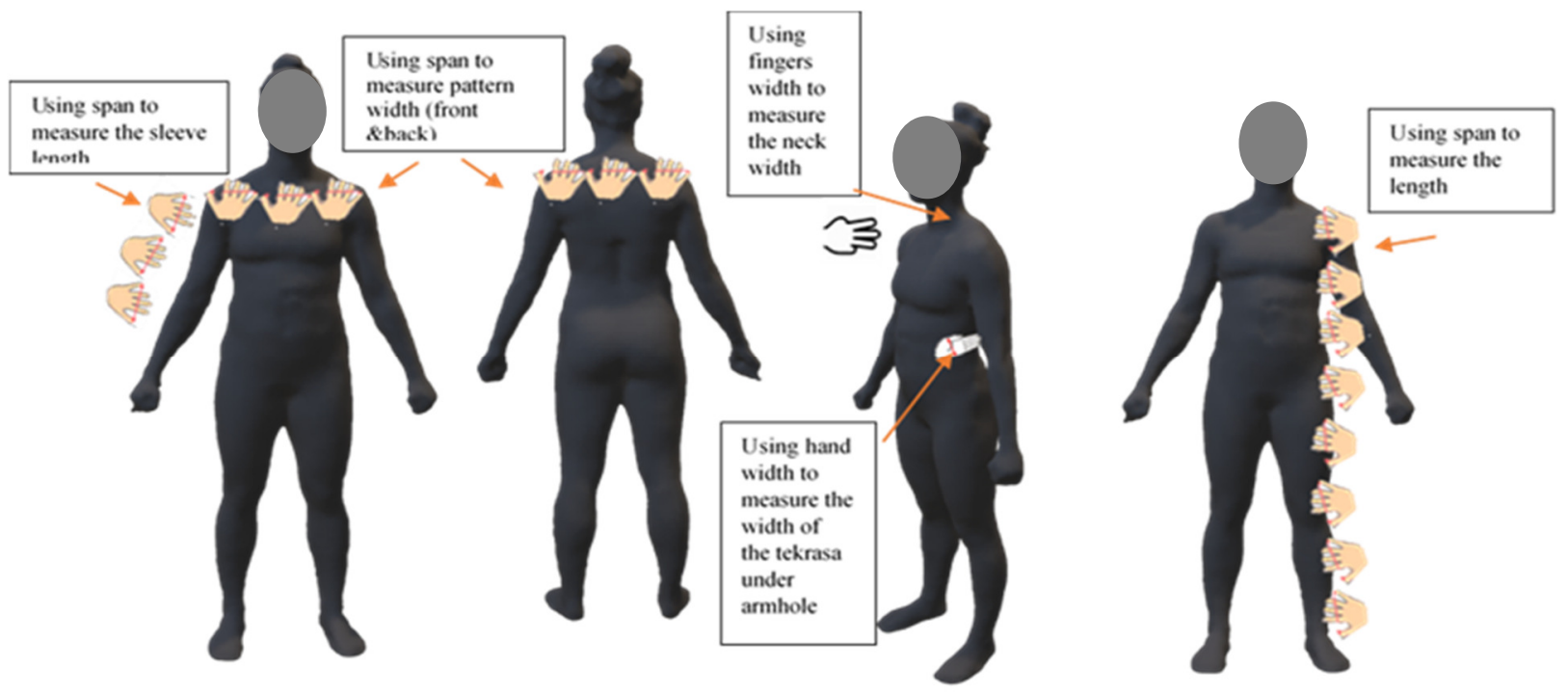

Figure 3 shows the technique of tailors to make Sawwan garment 
In contrast, body scanners offer an efficient way in which to obtain a large number of highly accurate measurements in a short period of time [12]. Therefore, the current study will demonstrate the benefits of body scanning technologies for the garment industry by showing how the data produced can improve the Sawwan garment so that it truly fits the body of the wearer in a way that is not possible when relying on the small number of traditional measurements. Creating flat patterns requires accurate measurements to be taken and care is needed in order to ensure that the resulting garments are wellfitted. In order to take the necessary measurements, modern methods were employed (Profili, 1949; and Aldrich, 2015) and these also helped with positioning and pattern construction. [12:123] note that "Human measurement is the basis for creating well-fitting and functioning clothing and is central to the communication of garment size." As such, by applying the modern methods, the current study is able to supplant the traditional physical methods with additional measurements that provide a truer interpretation of the body's form. For instance, this will involve measuring the neck's true dimensions rather than relying on a hand width. Based on the output from a 3D body scanner, the following table lists the measurements required when drafting a Sawwan garment. This helps to demonstrate the need for accurate measurements and the ways in which this can influence the resulting size of the finished garment including how well it fits, how comfortable it is to wear, how symmetrical it is and its appearance. 3D scanners are able to identify the key landmarks and these are used to arrive at the relationships of body measurements for use in pattern making. The garment is styled to fit the form of the body. The shape was determined by their choice of method for taking measurements because they would only use width measurements instead of taking circumference measurements which is now routine procedure when using 3D body scanners to take measurements. As such, this study will analyse the latest methods and utilise these to create a Sawwan pattern and create garments that modern Saudi Women want to wear.

Table 1 the new measurements extracted from 3D body scan to enhance Sawwan garment

\begin{tabular}{|c|c|c|c|}
\hline Measurement & $\begin{array}{l}\text { Definition of the } \\
\text { measurement }\end{array}$ & Illustrations & Note \\
\hline \multicolumn{4}{|l|}{ 1-Circumferences } \\
\hline Front neck depth & $\begin{array}{l}\text { Measure the vertical } \\
\text { measurement from the centre } \\
\text { neck level to the neck points. }\end{array}$ & & \multirow{3}{*}{$\begin{array}{l}\text { Take actual neck girth [13] } \\
\text { rather than the width of the } \\
\text { fingers that have used in } \\
\text { traditional Sawwan } \\
\text { pattern, this method gives } \\
\text { accurate result due to take } \\
\text { the real neck size of the } \\
\text { depth and width. } \\
\text { Some authors suggest that } \\
\text { to measure the base of the } \\
\text { neck the tape measure } \\
\text { should be close to the } \\
\text { collar [14,15,16].And this } \\
\text { method might be difficult to } \\
\text { get the accuracy number, } \\
\text { especially for beginner } \\
\text { people. }\end{array}$} \\
\hline Front neck width & $\begin{array}{l}\text { Neck width can be extracted } \\
\text { directly from distance between } \\
\text { the side neck points. }\end{array}$ & & \\
\hline Back neck depth & $\begin{array}{l}\text { It is a difference between the } \\
\text { side neck and back neck }\end{array}$ & & \\
\hline
\end{tabular}




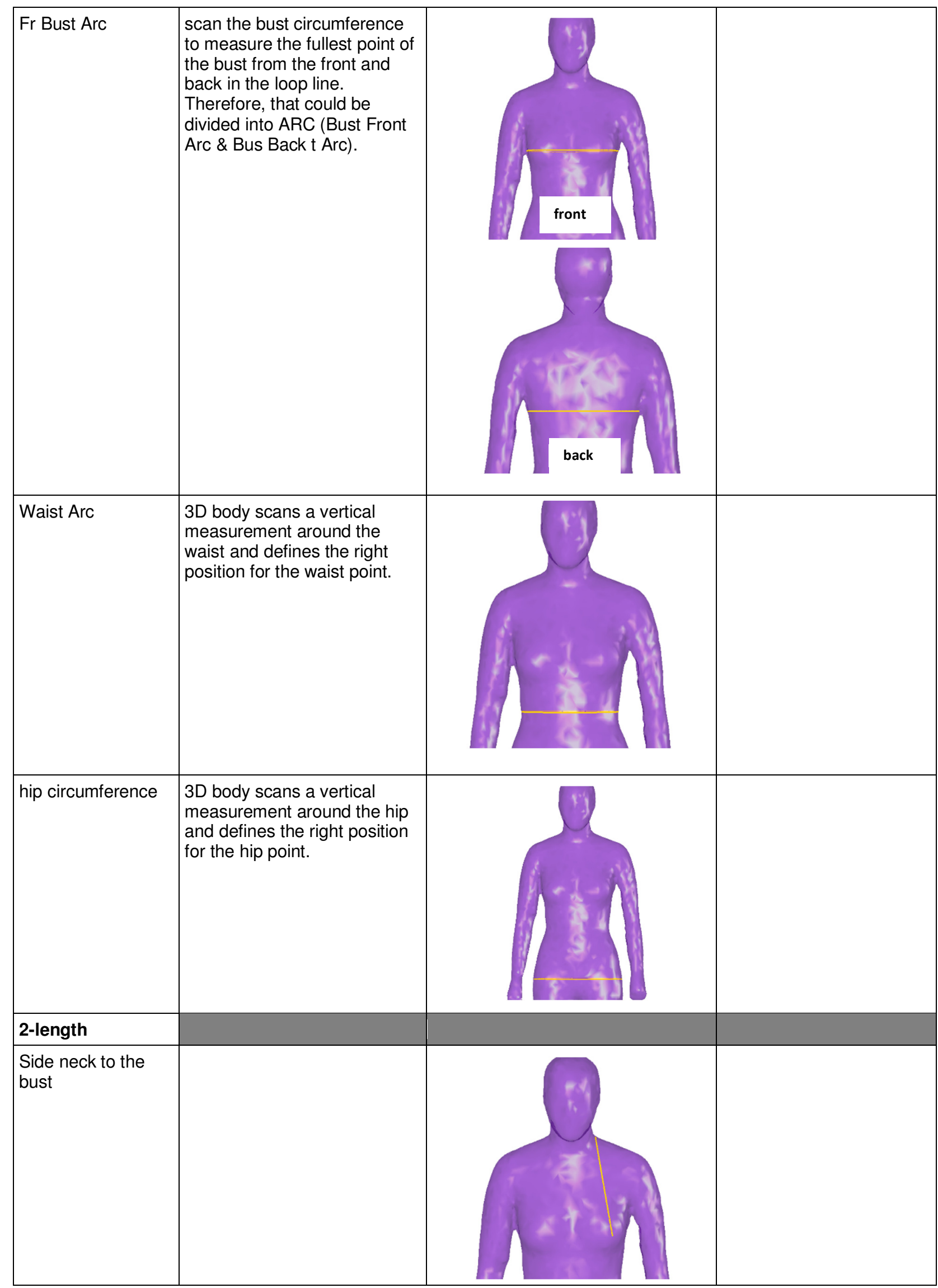




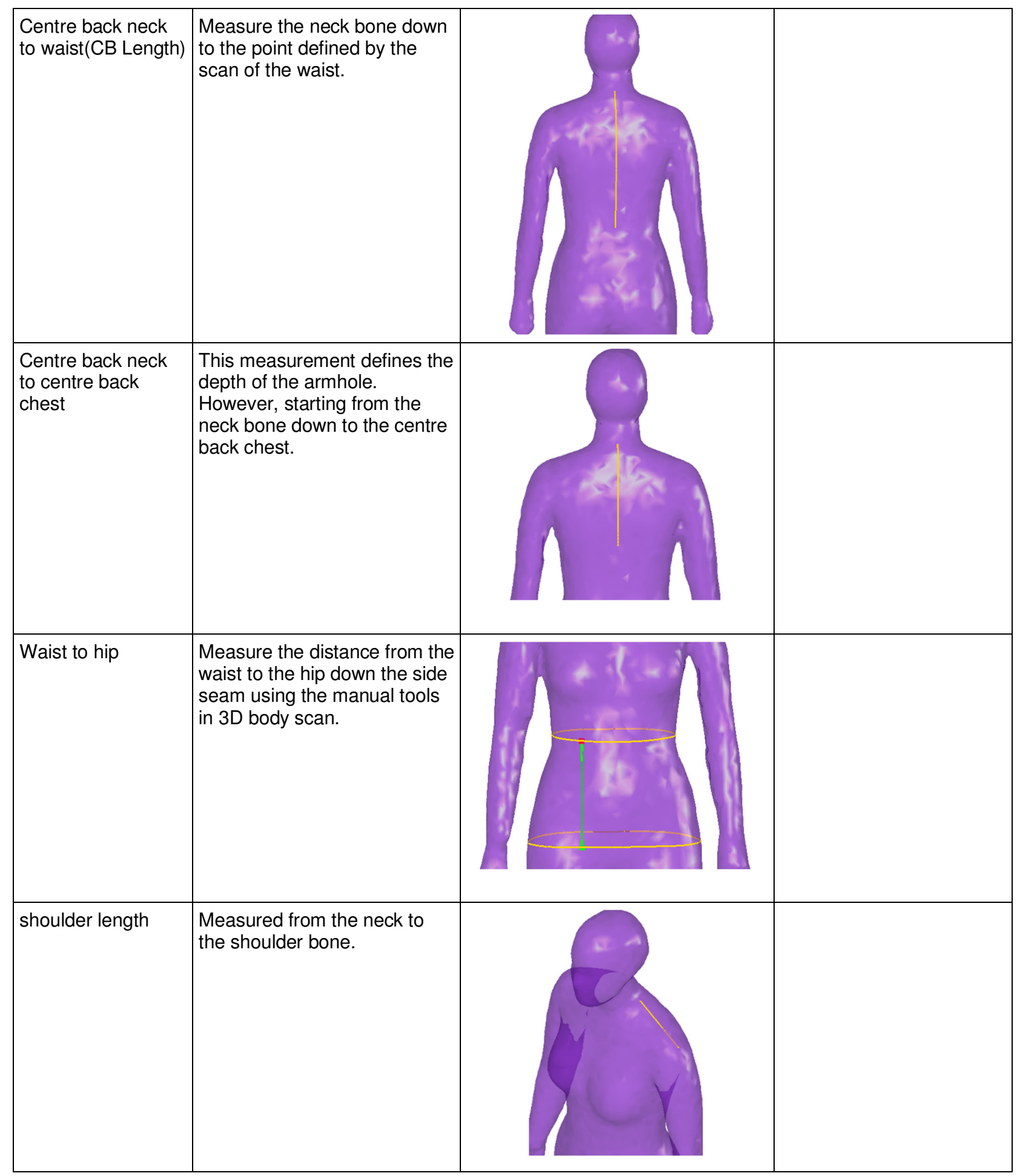




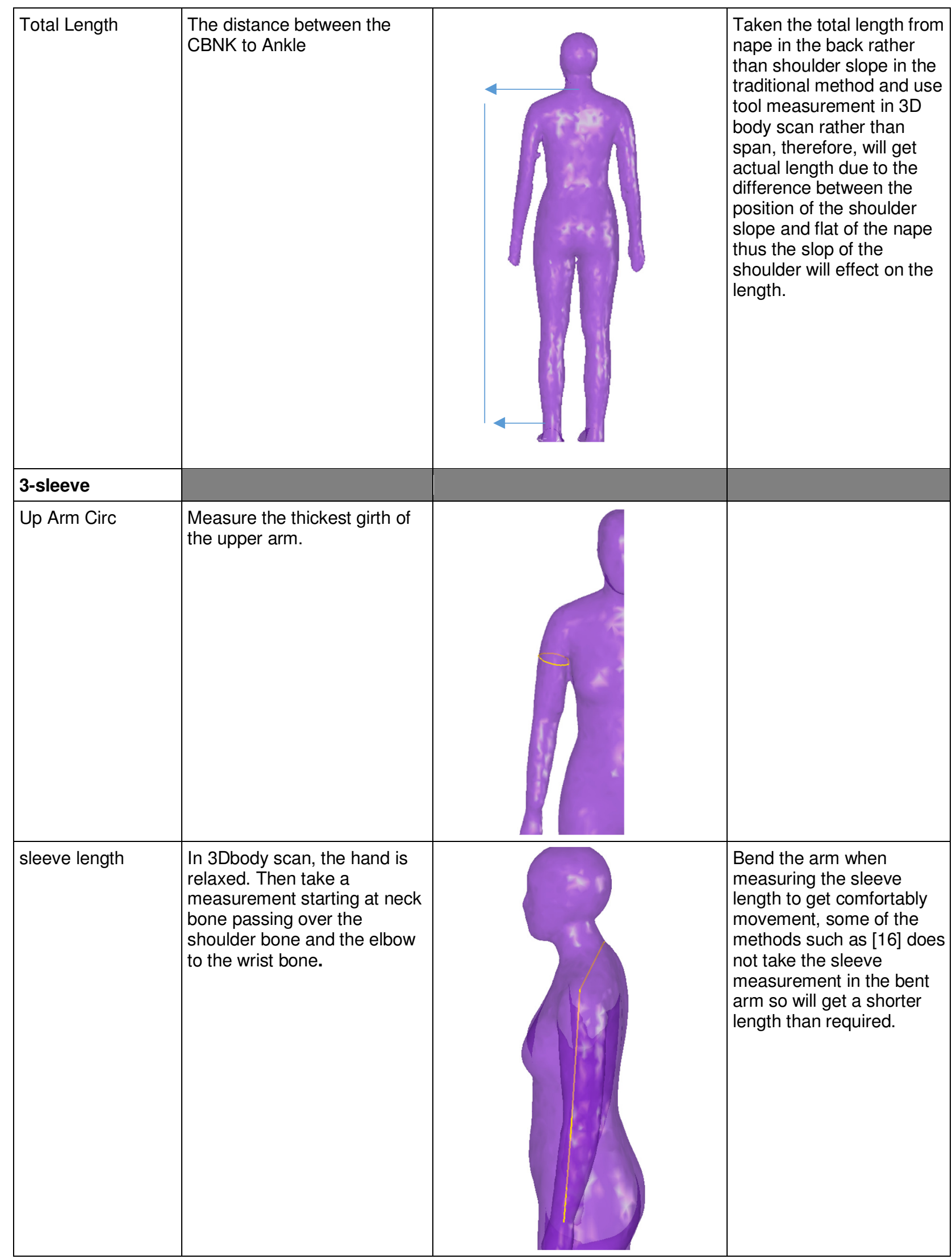




\begin{tabular}{|l|l|l|}
\hline wrist Circ & $\begin{array}{l}\text { Circle line to measure the } \\
\text { wrist and get Measure the } \\
\text { thickest girth of the upper arm. } \\
\text { Measure the thickest girth of } \\
\text { the upper arm. a sufficient } \\
\text { amount for comfort. }\end{array}$
\end{tabular}

\section{Conclusions}

It is known that body scanners provide highly accurate measurements of the human body's dimensions and these can be used to help improve on existing methods of pattern making. However, in order for the full potential of this technology to be realised, further research into the measurement process is needed so that pattern making can increasingly become automated. The future of pattern making lies in the development of analysis systems that utilise all measurements used in established pattern making methods. By doing so, it will be possible to assimilate systems into the conventional methods currently being applied.

Research of this nature is needed to better understand pattern theory and how measurements are taken from the human form translate into a pattern shape. Moreover, there remain unanswered questions regarding the positioning of the waist and bust darts. It is also distinctly possible that developing the analysis tools could help to determine the optimal length of darts, whilst studying the widths, depths and arcs could yield useful information about dart openings.

The data produced by 3D body scanners are obtained in a highly efficient manner and are ideal for use in patternmaking. Crucially, if the data are programmed in an appropriate manner, they can effectively result in significant advances in how pattern blocks are produced for the purposes of mass production and also made-to-measure.

\section{Acknowledgements}

Thanks are due to Al Bahah University for providing the author with the ability to fulfil her potential and acquire new skills that can be shared with others in future.

\section{References}

[1] Nader, K. and Maglan, S. (2010) Traditional dress in Saudi Arabia. King Fahad. Makkah.

[2] Mimny, E. (1996) Study the Development of Traditional Clothing inherited and Accessorise for Saudi Women in Taif Region. Umm AIQura University, Meccah, The Kingdom of Saudi Arabia.

[3] Almalki, F. (2017) Remaking the Past: Fashion Heritage Futures in Bani Malik Al Hijaz, Saudi Arabia. Master Thesis, University of Wolverhampton.

[4] Albasam, L. (1985) Traditional heritage of women's clothing in Najd. (1st ed). Qatar: Center for Folklore of the Arab Gulf States.

[5] Ajaji, T. (2005) Traditional Women's Costumes in the northern region of Saudi Arabia. College of Education for Home Economics, Riyadh, Saudi Arabia.

[6] Iskandarani, B. (2006) Traditional Clothing for Women and Bride Clothes in Medina. Scientific algorithm for publication and distribution.

[7] ill, S. et al. (2018) 'Scan to Pattern: How Body Scanning Can Help Transform Traditional Methods of Creating Pattern Blocks', pp. 16-17. doi: 10.15221/18.236. 
[8] E. Bye, K. L. Labat, and M. R. Delong, "Analysis of Body Measurement Systems for Apparel," Cloth. Text. Res. J., vol. 24, no. 2, pp. 66-79, Mar. 2006.

[9] Istook, C. L. and Hwang, S. J. (2001) '3D body scanning systems with application to the apparel industry', Journal of Fashion Marketing and Management, 5(2), pp. 120-132. doi: 10.1108/EUM0000000007283.

[10] McKinney, E. et al. (2017) 'Body-to-Pattern Relationships in Women's Trouser Drafting Methods: Implications for Apparel Mass Customization', Clothing and Textiles Research Journal, 35(1), pp. 1632. doi: $10.1177 / 0887302 X 16664406$.

[11] Gill, S. and Chadwick, N. (2009) 'Determination of ease allowances included in pattern construction methods', International Journal of Fashion Design, Technology and Education, 2(1), pp. 23-31. doi: 10.1080/17543260903018990.

[12] Gill, S. and Parker, C. J. (2017) 'Scan posture definition and hip girth measurement: the impact on clothing design and body scanning', Ergonomics. Taylor \& Francis, 60(8), pp. 1123-1136. doi: 10.1080/00140139.2016.1251621.

[13] A. Beazley, "Size and fit: Procedures in undertaking a survey of body measurements - Part 1," J. Fash. Mark. Manag., vol. 2, no. 1, pp. 55-85, 1997.

[14] Beazley,A. and Bond, T. (2003) Computer-Aided Pattern Design \&Product Development. Blackwell Science, Oxford.

[15] Aldrich, W. (2015) Metric Pattern Cutting for Women's Wear. (6th ed). NJ, USA: Wiley.

[16] Profili (1949) Profili Method for teaching sewing. (1st ed). Shindler Press Cairo. 